\title{
ロジンサイズ剤の紙表面におけるキャラクタリゼーション ーロジンサイズ剤の表面被覆率と吸液特性との関係一
}

大茞省印刷局研究所 尾崎 靖

東京農工大学農学部 俈渡 篤

\section{Surface Characterization of Rosin Sizing Agents on Paper - Relationship between Surface Coverage Ratio of Rosin Sizing Agents on Pulp Fiber and the Liquid Absorption Characteristies -}

\author{
Yasushi Ozaki ${ }^{* 1}$ and Atsushi Sawatari*2 \\ ${ }^{* 1}$ Research Institute, Printing Bureau,Ministry of Finance, 6-4-20, Sakawa, Odawara-City, Kanagawa, \\ 256-0816 Japan \\ ${ }^{* 2}$ Faculty of Agriculture, Tokyo University of Agriculture and Technology, 3-5-8, Saiwaicho, \\ Fuchu-City, Tokyo, 183-8509 Japan
}

\begin{abstract}
The relationship between the surface coverage ratio of rosin sizing agents on pulp fiber and the liquid absorption characteristics was examined. The surface coverage ratio of rosin on paper sheets was estimated by the degree of surface carbon atom concentration, which was obtained from the ESCA angle-dependent technique. The Stöckigt sizing degree, the rate of change in contact angle with the elapse of time and the magnitude of slope of the line in dynamic contact angle were adopted as the liquid absorption characteristics.

In the case of the emulsion type rosin, the liquid absorption characteristics changed notably by heat treatment in comparison to those in the soap type rosin.

The Stöckigt sizing degree increased with the surface coverage ratio, and the rate of change in contact angle with elapse of time and the magnitude of slope to the line in dynamic contact angle decreased with the increase in the surface coverage ratio. Furthermore, the rate of change in contact angle and the magnitude of slope to the line in dynamic contact angle decreased remarkably by heat treatment.
\end{abstract}

(Received 5 January, 1999 ; Accepted 25 February, 1999)

\section{1. 緒言}

サイズ剷の添加による紙の表面変化は，用新の印刷適 性を評価する上で極めて重要である。内面添加凬である ロジンサイズ削は抄紙前の紙料中に湿合され, 定着郕(硫

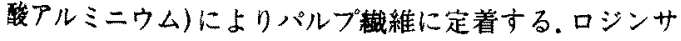
イズ凪の添加量が1\%以下のわずかな量であっても，製 䉻後の籷表面に大きいサイズ效果を付与する。このこと
は，一つにはサイズ剤がパルプ械維表面に多く定着して いることによる。パルプ㦵維の表面の一部をサイズ戍が 被覆することは，EPMA，ESCAおよびTOF-SIMSを用 いてロジンサイズ刘の紙表面における分布を観祭した研 究により明らかにされている[1].ささらにESCA角度変化 法を用いて，ロジンサイズ削を添加したパルプからの紙 について表層の炭素原子比率から、ロジンサイズ戍の最 表面における被覆率が算出できた[2]. 
ここでは，得られたロジンサイズ剤の最表面の被覆率 とシートの昅液特性との関係について検討した結果を報 告する.

\section{2. 実験}

\section{1 試料}

ロジンサイズ耠としてソープ型ロジン溶液(ハリマ化成 (制L-750, 濃度30\%) と,エマルション型ロジン溶液(ハ リマ化成(制製NES-405, 濃度 $50 \%$ ) を使用した。広葉樹漂

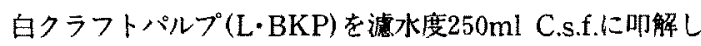
た. 各ロジンサイズ剤を $0,0.3 ， 0.5 ， 1.0$ おび2.0\%の 添加量でパルプスラリ一へ加え，硫酸アルミニウムを $1.2 \%$ 添加して定着後, 坪量 $60 \mathrm{~g} / \mathrm{m}^{2}$ の手すきシートを調製した. そして，ウエットプレスした手すきシートを，20ㄷ 相対 湿度 $65 \%$ において 1 日以上乾燥させて調湿した。また，

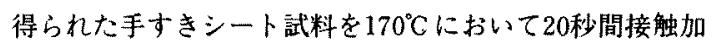
熱処理した試料も用いた。

\section{2 表面被覆率の筆出[2]}

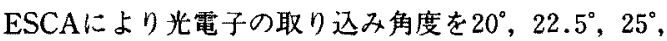
$30^{\circ}, 45^{\circ}$ おじ $90^{\circ}$ として各ロジン添加昘手すきシートにつ いての測定を行ったナロースキャンモード(パスエネル

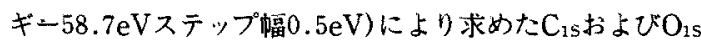

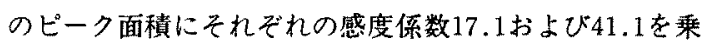
じて表層の炭素原子比率 Nc(atom\%)を求めな.ここで $\mathrm{N}_{\mathrm{c}}+$ $\mathrm{N}_{0}=100$ であり，Noは酸素原子比率である、次に，各々 の試料について得られたデータから取り込み角度を0゚に外 捙し，各試料の最表面のNcを求めた。るして，ロジンの 表面被覆乘を $\phi_{\mathrm{c}}(\%)$ とすると, $\phi_{\mathrm{c}}$ はStrömらの式(1)によ り求めることができる[3].

$$
\phi_{\mathrm{c}}=\left[\left(\mathrm{N}_{\mathrm{cp}}-\mathrm{N}_{\mathrm{co}}\right) /\left(\mathrm{N}_{\mathrm{c100}}-\mathrm{N}_{\mathrm{CO}}\right)\right] \times 100
$$

ここで, $\mathrm{Ncp}(\%)$ は各試料の最表面の $\mathrm{Nc}, \mathrm{N}_{\mathrm{co}}(\%)$ は口 ジンを添加していないL・BKPシートの最表面のNc, N 100 (\%)は各々ソープ型およU゙エマルション型サイズ昘を $105{ }^{\circ} \mathrm{C}$ において 5 時間乾燥されて得られた固体の表層部分をか き取った表面のESCAの強度から求めたNcである. 加熱 前後では各々， $\mathrm{N}_{\mathrm{co}}=58.2, \mathrm{~N}_{\mathrm{co}}=58.60$ 值が得られ，ま． たソーブ型ロジンサイズ刜についてはN $\mathrm{N}_{\mathrm{c} 100}=85.7$, エマ ルション型ロジンサイズ剤については $\mathrm{N}_{\mathrm{c} 100}=84.8$ の傎が 得られた。

\section{3 手すきシート中の平均㴗度の算出 $[4]$}

気相中で手すきシート中のロジンサイズ刘をOsO4 クラベル化処理を施した. 次にEPMAにおいてOsM $\alpha$ 線 により表面の $200 \mu \mathrm{m} \times 150 \mu \mathrm{m}$ 面積におけるマッピング 分析を行った。マッピングの平均濃度は,OsM $\alpha$ 表面マ ッピング領域全体におけるオスミウムの定量值である。 この值は, 全面に金属才スミウムが存在するときの濃度
を $100 \mathrm{wt} \%$ としている.オスミウムの平均灙度はX線強度 と濃度 $(w t \%) と の$ 直線関係から算出したここでは, EPMA を用いて上記のように求めたこの濃度を以下EPMA平圴 濃度と呼ふこととする。なお，EPMA平均濃度はオスミ ウムの付加量が增えれば電子線の浸透深さが浅くなるた め，より浅い媣さ領域を検出していることになる。

\section{4 ステキヒトサイズ度の測定}

JIS P8122に準して各試料のステキヒトサイズ度を测定 した.

\section{5 接触角の变化速度の測定}

接触角の測定は液体に蒸留水を使用する液滴法により， 接触角計(協和界面科学(柇整CA-X型)を用いて 5 秒後およ ひ60秒後の接触角劣測定し, 各々 5 回の測定を行った。 結果は, 次式 (2)により算出される接触角の平均变化速度 (度/秒)として表した。

$\mathrm{R}=\left(\mathrm{C}_{5}-\mathrm{C}_{60}\right) / 55$

$\mathrm{R}$ : 接触角の平均变化速度 $($ 度/秒)

$\mathrm{C}_{5}: 5$ 秒後の平均接触角

$\mathrm{C}_{60}: 60$ 秒後の平均接触角

\section{6 功的接策角の測定}

動的接角の測定は, 接触角計(協和界面科学儌 X型) と動的接触角解析システム(協和界面科学构整ZEROI型)により液滴滴下 2 秒後から30秒まで 4 秒間隔にわけ る接触角を求めた。

\section{3. 結果と考察}

\section{1 表面被後率とステキヒトサイズ度との䦕係}

四 1 に,シート表面におけるロジンの表面被覆率とス テキヒトサイズ度との関係を示す、ソープ型ロジの場 合には，ロジンの被䬸率の増加に伴ってステキヒトサイ ズ度は高くなり，加熱処理によってサイズ度のわずかな 向上が認められる。エマルション型ロシンのの場合にもロ ジンの被覆率の增加に伴ってステキヒトサイズ度は大き くなるが，加熱処理前においては被覆率の增加に对して ステキヒトサイズ度の增加は小さく，加熱してはじめて サイズ度の著しい向上が認められた。

\subsection{EPMA平均流度とステキヒトサイズ度との関保}

表 1 およU゙表 2 にソープ型ロシンおよU゙エマルション 型ロジンのL・BKP手すきシートのEPMA平均濃度を示す。 EPMAに上り得られた平均濃度は，表面から約 $7 \mu \mathrm{m} の$ 深 さ領域における值であるので[1],シート内部とくに峨維 壁のロジン量に対応していると考えることとする。ロシ ンの表面被覆率は表面における水浸透抑制勃果の要因の 一つであり，EPMA平均濃度はシート内部における水浸 透抑制効果の要因の一つであると考えられる。

そこで，图 2 にEPMA平均濃度とステキヒトサイズ度 
(A)

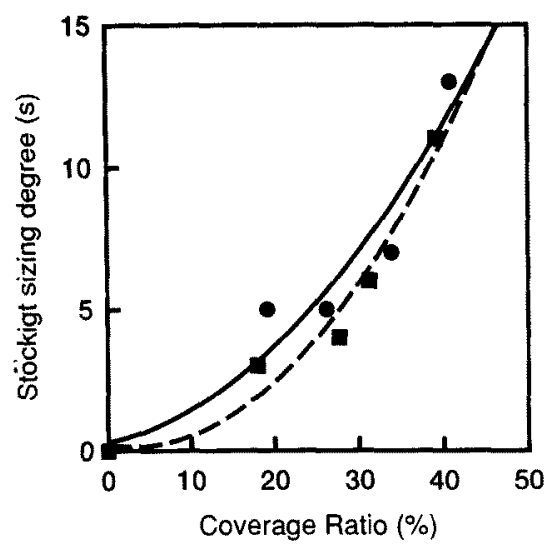

(B)

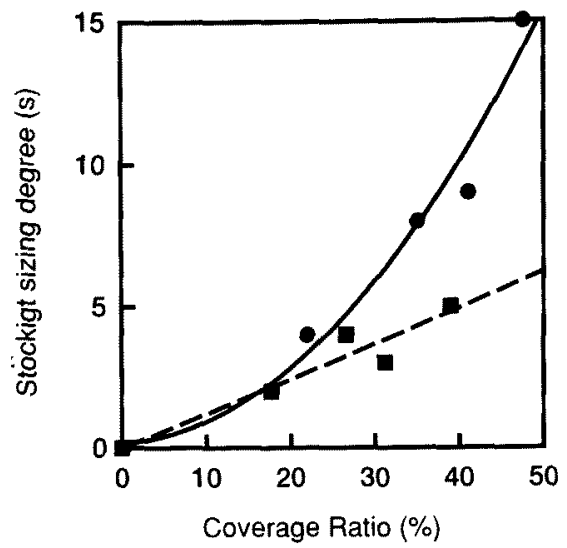

Fig. 1 Relationship between Stöckigt sizing degree and the rosin apparent coverage $(\%)$ of $\mathrm{L} \cdot \mathrm{BKP}$ handsheet (A) Soap type rosin, (B) Emulsion type rosin, before heat treatment $(\boldsymbol{D})$, after heat treatment $(\boldsymbol{O})$

Table 1 The average concentration* $\%$ of OsM $\alpha$ images on the $\mathrm{L} \cdot \mathrm{BKP}$ handsheet added with soap type rosin

\begin{tabular}{lccccc}
\hline rosin added $(\%)$ & 0.0 & 0.3 & 0.5 & 1.0 & 2.0 \\
\hline before heat treatment & 0.24 & 0.34 & 0.44 & 0.64 & 0.85 \\
after heat treatment & 0.24 & 0.69 & 0.60 & 0.93 & 1.14 \\
\hline
\end{tabular}

*The average concentration $(\%)$ was calculated from each $0 s \mathrm{M} \alpha$ image of surface of the handsheet.

Table 2 The average concentration* $\left.{ }^{*} \%\right)$ of OsM $\alpha$ images on the $\mathrm{L} \cdot \mathrm{BKP}$ handsheet added with emulsion type rosin

\begin{tabular}{lccccc}
\hline rosin added $(\%)$ & 0.0 & 0.3 & 0.5 & 1.0 & 2.0 \\
\hline before heat treatment & 0.24 & 0.51 & 0.34 & 0.44 & 0.96 \\
after heat treatment & 0.24 & 0.55 & 0.54 & 0.85 & 1.50 \\
\hline
\end{tabular}

*The average concentration $(\%)$ was calculated from each OsM $\alpha$ image of surface of the handsheet.

との関保を示す。ソープ型ロジンの場合, EPMA平均濃 度の增加によりサイズ度の增加がみられ，加熱処理によ つて平均濃度は增加する。しかし，ステキヒトサイズ度 はあまり增加しなかった。一方エマルション型ロジンの 場合, 加熱処理を行うことによって，平均濃度とステキ ヒトサイズ度のどちらも著しく增加した。

\section{3 表面被徣事 $\times$ EPMA平均湌度とステキヒトサイズ 度との関保}

表面被覆率とEPMA平均濃度の相乘効果を求めるため に，図 3 に被覆率とEPMA平均濃度を掛计合わせた值と ステキヒトサイズ度との関係を示した。その結果ソープ
型ロジンの場合, 被覆率とEPMA平均濖度を挂け合わせ た値が増加するに従って，ステキヒトサイズ度も増加し たが，加熱前後においてはほほ近い結果を示した。一方 エマルション型ロジンの場合，加熱前と比較して加熱後 において被覆率とEPMA平均濃度を掛け合わせた值は著 しく增加し，ステキヒトサイズ度も增加した．図1一四3 の結果は、ロジンの表面被覆率だけでなく，パルプ縺維 壁中のロジンの濃度もステキヒトサイズ度にとって大き な因子であり，両因子を考察する必要があることを示唆 している.

\section{4 表面被覆茟と接角の変化速度の関係}

図4に，シート表面におけるロジンの表面被覆率と接 触角の平均变化速度 $(R)$ との関係を示す。この図から, 接 触角の平均変化速度は被覆率の增加によって減少するが, 加熱前後において大きな変化を示した，また，この結果 は，ステキヒトサイズ度の結果とは異なり、ソープ型口 ジンの場合ですら熱処理によって接触角の減少速さが小 さくなり，熱処理の影響が著しいことを示している。

\subsection{EPMA平均灌度と接角の変化速度の闌係}

図 5 にEPMA平均濃度と接触角の平均変化速度 $(\mathrm{R})$ との 関係を示す、ソープ型およびエマルション型ともに加熱 処理を施すことによって接触角の変化速度は小さくなつ た. ソープ型とエマルション型を比較するとエマルショ

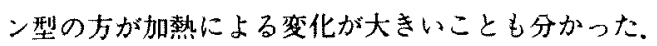

\section{6 表面被覆率 $\times \mathrm{EPMA}$ 平均湌度と接角角の变化速度 の関係}

図 6 に被覆率とEPMA平均濃度を掛け合わせた值と平 均変化速度 $(\mathrm{R})$ との関係を示才。被覆率とEPMA平均濃度 を掛け合わせな結果は図5の結果とはほ同じ挙動を示した。 
(A)

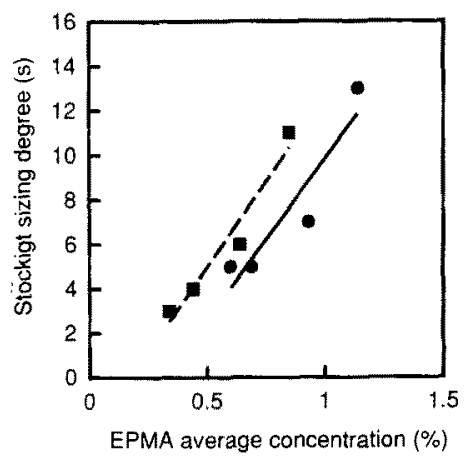

(B)

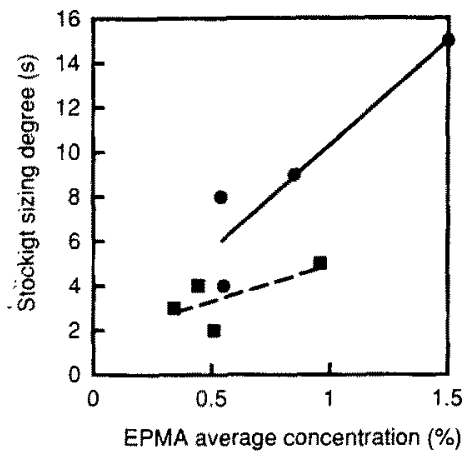

Fig. 2 Relationship between Stöckigt sizing degree and the rosin average concentration of L.BKP handsheet by EPMA

(A) Soap type rosin, (B) Emulsion type rosin, before heat treatment $(\boldsymbol{\square})$, after heat treatment

(A)

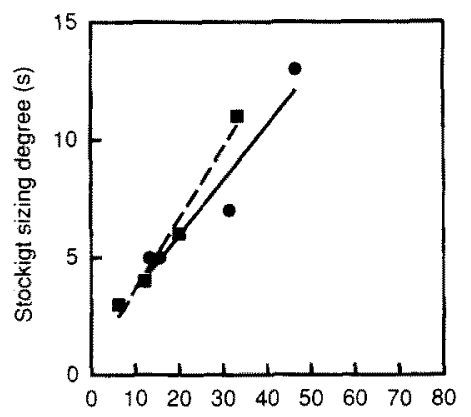

Coverage ratio $\times E P M A$ average concentration
(B)

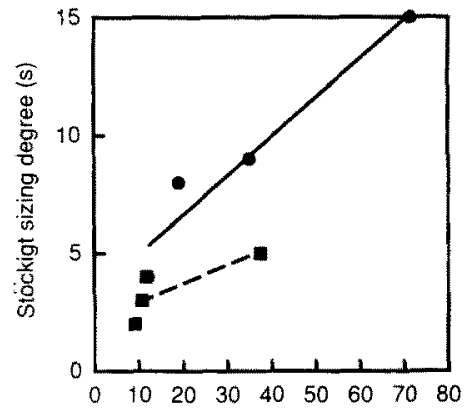

Coverage ratio XEPMA average concentration

Fig. 3 Relationship between Stöckigt sizing degree and the rosin apparent coverage $\times$ EPMA average concentration

(A) Soap type rosin, (B) Emulsion type rosin, before heat treatment ( $\mathbf{D})$, after heat treatment ( $)$
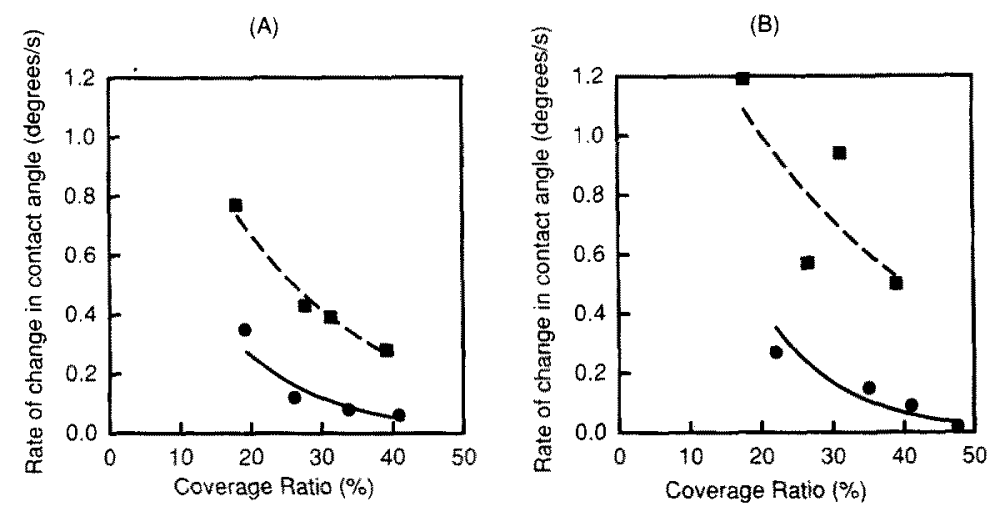

Fig. 4 Relationship between the rate of change in contact angle (R) and the rosin apparent coverage (\%) of $L \cdot B K P$ handsheet

(A) Soap type rosin, (B) Emulsion type rosin, before heat treatment $(\boldsymbol{D})$, after heat treatment 

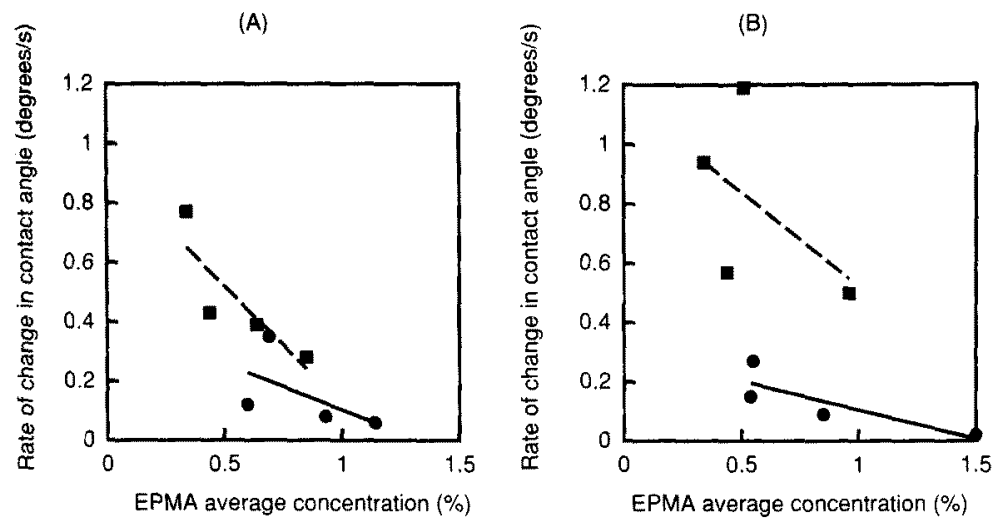

Fig. 5 Relationship between the rate of change in contact angle and the rosin average concentration of L. BKP handsheet by EPMA

(A) Soap type rosin, (B) Emulsion type rosin, before heat treatment $(\mathbf{\square})$, after heat treatment $(\boldsymbol{C}$

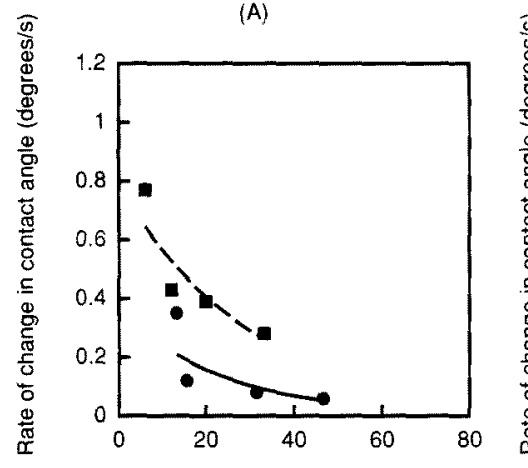

Coverage ratio $X E P M A$ average concentration

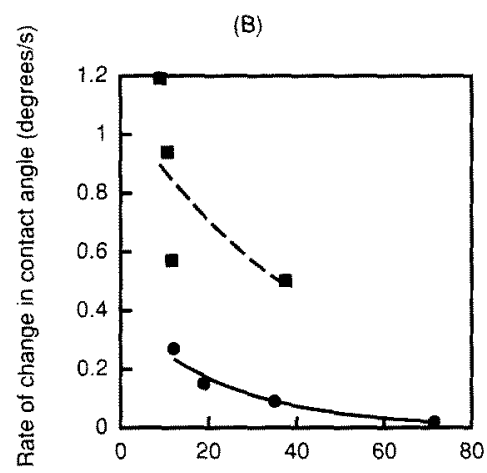

Coverage ratio $X E P M A$ average concentration

Fig. 6 Relationship between the rate of change in contact angle and the rosin apparent coverage $\times$ EPMA average concentration

(A) Soap type rosin, (B) Emulsion type rosin, before heat treatment $(\mathbf{D})$, after heat treatment (

\section{7 表面被覆率と趿的接触角の時間变化の関係}

图7および图 8 にソープ型およびエマルション型ロジ ンサイズ剤を添加したL・BKP手すきシート表面の動的接 触角を示す。この結果から，备々の動的接触角データか ら得られた回帰直線の傾き求奴。この傾きは，接触 角の時間変化を示す。こてで，動的接触角の傾きの絶対 值とシート表面におけるロジンの表面被覆率との関係を 图9に示す。ソープ型ロジンサイズ剂の場合，被覆率の 增加により, 動的接触角の傾きの絶対值は小さくなり, 加熱後はさらに小さくなった.エマルション型ロジンサ イズ剤の場合には，ソープ型ロジンサイズ削と比較して 加熱前においては動的接触角の㑯きの絶对值は非常に大 きかった. 熱処理を行うことによりその值は小さくなつ たが、ソープ型ロジンの場合よりも高い結果となった。
また, EPMA平均濃度扝よび表面被覆率 $\times$ EPMA平均 濃度と動的接触角の傾きの関係は，図 5 および 6 とほほ 類似の結果を示した。

これらの結果をまとめると，1)ロジンによるパルプ緎 維表面の被䧻率が大きくなるとステキヒトサイズ度は大

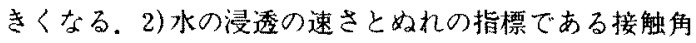
の減少速さは被磧率が大きくなると小さくなり，彗処理 によっても著しく小さくなる。

これらのことは, 著者らの研究により得られな結果[4], すなわち、ソープ型ロジンサイズ剂の堭合，加熱萠でも かなり水の漫透抑制効果を示したが，加熱することによ ってさらに抑制されること，そして、エマルション型ロ ジンサイズ剤の場合，加熱により水の漫透㸝制效果が著 しく向上したことと良く符合している. 
(A)

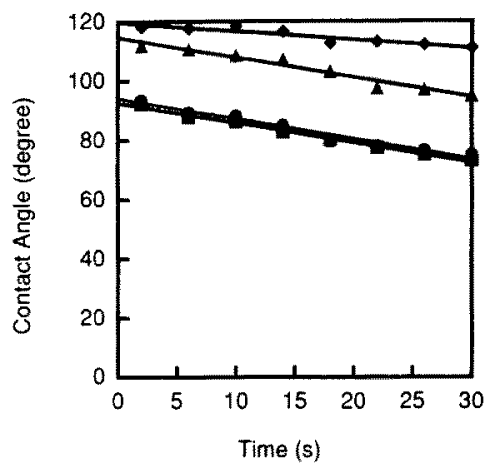

(B)

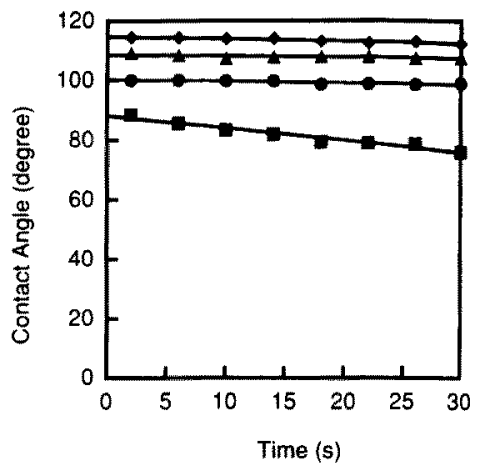

Fig. 7 Dynamic contact angle on $L \cdot B K P$ handsheet added with soap type rosin

(A) before heat treatment, (B) after heat treatment

Sample : $L \cdot B K P$ handsheet, which was added with soap type rosin $0.3 \%($

$0.5 \%(0), 1.0 \%(\mathbf{\Delta})$ and $2.0 \%(\bullet)$

(A)

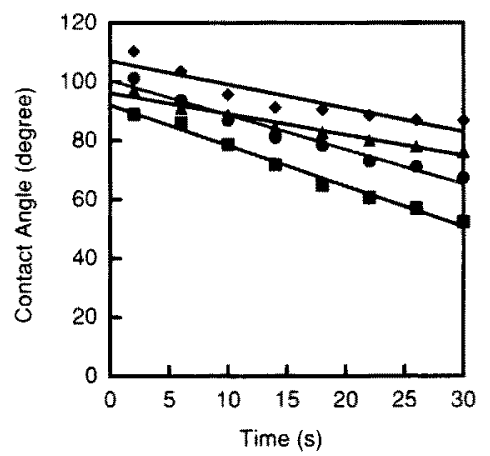

(B)

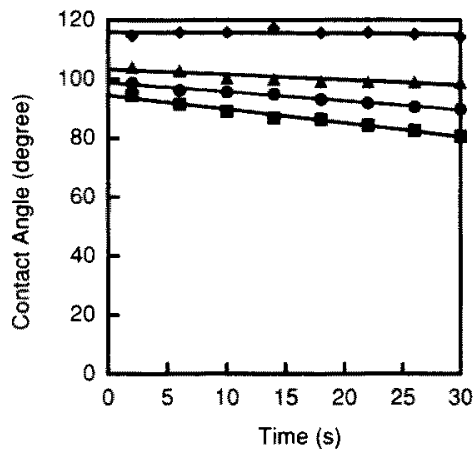

Fig. 8 Dynamic contact angle on L.BKP handsheet added with emulsion type rosin

(A) before heat treatment, (B) after heat treatment

Sample : L.BKP handsheet, which was added with emulsion type rosin $0.3 \%$

$0.5 \%(\bigcirc), 1.0 \%(\mathbf{\Delta})$ and $2.0 \%(\bullet)$

(A)

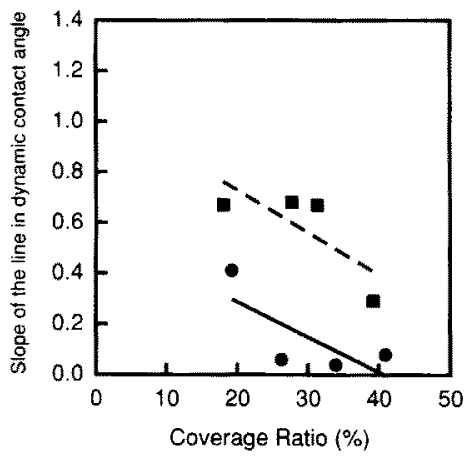

(B)

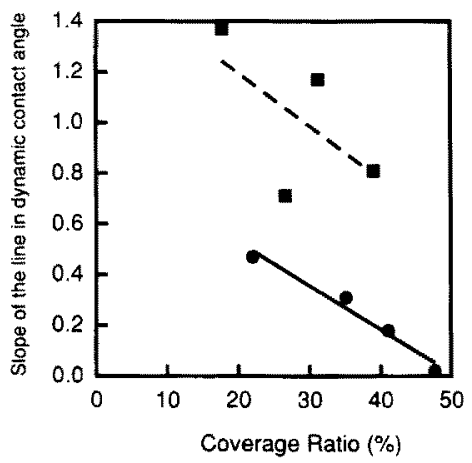

Fig. 9 Relationship between slope of the line in dynamic contact angle (Fig.7 and 8) and the rosin apparent coverage of $L \cdot B K P$ handsheet by the ESCA angle dependent technique (A) Soap type rosin, (B) Emulsion type rosin, before heat treatment ( $\square$ ), after heat treatment $(\mathbf{C}$ 
また図 3 と図6の結果は，水の浸透㧕制効果はロジン ク表面被覆率だけでなく，䑰維壁内部のロジン濃度も考 虑すべき因子であることを示唆していると考えられた。

\section{女献}

1. Y. Ozaki and A. Sawatari, Nord. Pulp Pap. Res. J., $12(4), 260(1997)$.
2. Y. Ozaki and A. Sawatari, Sen'i Gakkaishi, 55(2), 57 (1999).

3. G. Ström and G. Carlsson, J. Adhesion Sci. Technol., 6(6), 745(1992).

4. Y. Ozaki and A. Sawatari, Sen'i Gakkaishi, 54 (9), 467 (1998). 